\title{
A novel role for the apoptosis inhibitor ARC in suppressing TNF $\alpha$-induced regulated necrosis
}

\author{
G Kung ${ }^{1}$, P Dai ${ }^{2}$, L Deng ${ }^{2}$ and RN Kitsis ${ }^{*, 1}$
}

TNF $\alpha$ signaling can promote apoptosis or a regulated form of necrosis. ARC (apoptosis repressor with CARD (caspase recruitment domain)) is an endogenous inhibitor of apoptosis that antagonizes both the extrinsic (death receptor) and intrinsic (mitochondrial/ER) apoptosis pathways. We discovered that ARC blocks not only apoptosis but also necrosis. TNF $\alpha$-induced necrosis was abrogated by overexpression of wild-type ARC but not by a CARD mutant that is also defective for inhibition of apoptosis. Conversely, knockdown of ARC exacerbated TNF $\alpha$-induced necrosis, an effect that was rescued by reconstitution with wild-type, but not CARD-defective, ARC. Similarly, depletion of ARC in vivo exacerbated necrosis caused by infection with vaccinia virus, which elicits severe tissue damage through this pathway, and sensitized mice to TNF $\alpha$-induced systemic inflammatory response syndrome. The mechanism underlying these effects is an interaction of ARC with TNF receptor 1 that interferes with recruitment of RIP1, a critical mediator of TNF $\alpha$-induced regulated necrosis. These findings extend the role of ARC from an apoptosis inhibitor to a regulator of the TNF $\alpha$ pathway and an inhibitor of TNF $\alpha$-mediated regulated necrosis.

Cell Death and Differentiation (2014) 21, 634-644; doi:10.1038/cdd.2013.195; published online 17 January 2014

Apoptosis is a highly regulated form of cell death characterized by cell shrinkage, fragmentation, and disposal without loss of plasma membrane integrity and inflammation. ${ }^{1}$ In contrast, the hallmarks of necrosis are plasma membrane dysfunction, cell and organelle swelling, and marked inflammation. ${ }^{2,3}$ Necrosis has traditionally been considered to be unregulated, but increasing evidence suggests that some forms of necrotic death are actively controlled. ${ }^{3-8}$

Regulated necrosis mediated by death receptors, termed necroptosis, ${ }^{7}$ can be induced by the same death ligands that activate apoptosis, such as tumor necrosis factor $\alpha$ (TNF $\alpha$ ), Fas ligand, and TNF-related apoptosis-inducing ligand. ${ }^{8}$ Regulated necrosis initiated by binding of $\mathrm{TNF} \alpha$ to TNF receptor 1 (TNFR1) has been most extensively studied. ${ }^{3}$ Depending on cell type and conditions, TNF $\alpha$ can promote survival, apoptosis, or necrosis. ${ }^{3}$ Upon ligation by TNF $\alpha$, the receptor recruits TRADD (TNFR1-associated death domain), receptor interacting protein kinase 1 (RIP1), TNFR-associated factor 2 (TRAF2), cellular inhibitor of apoptosis 1 (clAP1), and clAP2. This membrane-localized supramolecular structure, known as complex I, activates nuclear factor- $\kappa \mathrm{B}$ (NF- $\kappa \mathrm{B}$ ) to promote cell survival. ${ }^{9-11}$ Internalization of complex I, dissociation of TNFR1, and deubiquitination of RIP1 give rise to cytosolic complex II, which also contains Fas-associated protein with a death domain (FADD), RIP3, and procaspase-8. ${ }^{9,12}$ Complex II allows for the activation of procaspase-8, leading to initiation of apoptosis through the classical caspase cascade. ${ }^{9}$ However, if caspase-8 activity is blocked, RIP1 and RIP3 kinases are activated and initiate multiple downstream mechanisms to bring about necrosis. ${ }^{12-17}$ Thus, in this scheme necrosis appears to be the default mechanism of cell death when apoptosis is blocked.

ARC (apoptosis repressor with CARD (caspase recruitment domain)) is an endogenous apoptosis inhibitor that is expressed under normal conditions in terminally differentiated cells ${ }^{18}$ and is markedly induced in a variety of cancers. ${ }^{19}$ ARC is unusual as it antagonizes both mitochondrial and death receptor apoptosis pathways. ${ }^{20}$ Inhibition of the mitochondrial pathway is mediated through direct interactions of ARC with Bax, suppressing Bax activation and mitochondrial translocation. The death receptor pathway is inhibited by $A R C$ binding to Fas and FADD, resulting in impaired assembly of the death-inducing signaling complex.

In this study, we discovered that ARC suppresses TNF $\alpha$-induced necrosis, as well as apoptosis, both effects dependent on the ARC CARD. This is observed in both cultured cells and intact animals. The mechanism involves the binding between ARC and TNFR1, which interferes with RIP1 recruitment and complex I formation.

\footnotetext{
${ }^{1}$ Departments of Cell Biology and Medicine, Wilf Family Cardiovascular Research Institute, Albert Einstein Cancer Center, and Diabetes Research Center, Albert Einstein College of Medicine, Bronx, NY, USA and ${ }^{2}$ Dermatology Service, Department of Medicine, Memorial Sloan-Kettering Cancer Center, New York, NY, USA ${ }^{*}$ Corresponding author: RN Kitsis, Departments of Cell Biology and Medicine, Wilf Family Cardiovascular Research Institute, Albert Einstein Cancer Center, and Diabetes Research Center, Albert Einstein College of Medicine, 1300 Morris Park Avenue, Bronx, NY 10461, USA. Tel: +718 4302609 ; Fax: +718 4308989 ; E-mail: richard.kitsis@einstein.yu.edu

Keywords: ARC; necrosis; apoptosis; TNF $\alpha$

Abbreviations: ARC, apoptosis repressor with a CARD; CARD, caspase recruitment domain; CHX, cycloheximide; clAP, cellular inhibitor of apoptosis; DD, death domain; DM, CARD-defective double-point mutant of ARC; ELISA, enzyme-linked immunosorbent assay; FADD, Fas-associated death domain; HA, hemagglutinin; HMGB1, high mobility group protein $\mathrm{B} 1$; $L D H$, lactate dehydrogenase; NF- $\kappa \mathrm{B}$, nuclear factor- $\kappa \mathrm{B}$; PARP, poly $A D P$-ribose polymerase; PI, propidium iodide; RIP1, receptor interacting protein kinase 1; shRNA, short hairpin RNA; siRNA, small interfering RNA; TNF $\alpha$, tumor necrosis factor $\alpha$; TNFR1, TNF receptor 1; TRADD, TNFR-associated death domain; TRAF2, TNFR-associated factor 2

Received 3.5.13; revised 15.11.13; accepted 25.11.13; Edited by J Silke; published online 17.1.14
} 


\section{Results}

ARC suppresses TNF $\alpha$-induced necrosis. Mouse L929 fibrosarcoma cells serve as a well-defined system in which TNF $\alpha$ treatment can elicit either apoptosis or necrosis. ${ }^{21,22}$ When administered in conjunction with the protein synthesis inhibitor cycloheximide ( $\mathrm{CHX})$, which promotes depletion of short-lived apoptosis inhibitors, TNF $\alpha$ induces apoptosis. On the other hand, the application of TNF $\alpha$ with a pancaspase inhibitor (e.g., z-VADfmk), or even TNF $\alpha$ by itself, is sufficient to induce necrotic death in L929 cells. ${ }^{21}$ We confirmed these properties of the system. TNF $\alpha+\mathrm{CHX}$, but not TNF $\alpha$ alone, induced cleavage of the caspase-3 substrate poly ADPribose polymerase (PARP), a classic marker of apoptosis ${ }^{23}$ (Figure 1b). Conversely, $\operatorname{TNF} \alpha$ alone, but not $\mathrm{TNF} \alpha+\mathrm{CHX}$, promoted cellular release of the chromatin-binding protein high mobility group protein B1 $(\mathrm{HMGB} 1)^{24}$ and lactate dehydrogenase (LDH), both markers of necrosis (Figure 1c and Supplementary Figure S1a).

$A R C$ is a well-characterized inhibitor of mitochondrial and death receptor apoptosis pathways. ${ }^{20}$ Accordingly, we hypothesized that inhibition of TNF $\alpha$-induced apoptosis by ARC would promote necrosis. We first tested the effect of ARC overexpression using L929 cells stably transduced with hemagglutinin (HA)-tagged ARC (Figure 1a). As anticipated, overexpression of ARC blocked PARP cleavage induced by $\mathrm{TNF} \alpha+\mathrm{CHX}$ (Figure 1b). Unexpectedly, however, ARC suppressed - rather than promoted - necrosis in response to treatment with $\mathrm{TNF} \alpha$ alone. This was demonstrated by inhibition of cellular release of HMGB1 and LDH and entry of propidium iodide (PI) (Figures 1c and d, and Supplementary Figure S1), all markers that reflect plasma membrane dysfunction, a defining characteristic of necrosis. Notably, inhibition of necrosis by ARC was substantial, as it was roughly equivalent to that resulting from the small molecule necrostatin-1, a specific and potent inhibitor of RIP1 kinase activity and necroptosis (Figure 1d and Supplementary Figure $\mathrm{S} 1 \mathrm{~b})$. These data indicate that overexpression of ARC in L929 cells inhibits TNF $\alpha$-induced necrosis.

CARD of ARC is necessary for suppression of TNF $\alpha$-induced necrosis. Death-folds are an evolutionarily conserved superfamily of motifs that mediate protein-protein interactions. Subtypes include the CARD, death domain (DD), death effector domain, and pyrin domain. ${ }^{25-27}$ We have previously demonstrated that endogenous ARC binds directly to endogenous Fas and FADD through interactions mediated by the ARC CARD and the DDs of Fas and FADD. ${ }^{20}$ Through these interactions, ARC inhibits the death receptor apoptosis pathway in a CARD-dependent manner. ${ }^{20}$ As several proteins that mediate TNF $\alpha$-induced necrosis contain death-fold motifs, we asked whether the ARC CARD is necessary for suppression of TNF $\alpha$-induced necrosis. We generated L929 cells with stable expression of the ARC double mutant L31F; G69R (denoted as DM), which is defective in CARD function. ${ }^{20,28}$ In contrast to wild-type $A R C, D M A R C$ was unable to inhibit TNF $\alpha$-induced necrosis, as assessed by HMGB1 and LDH release, and PI entry (Figure 2 and Supplementary Figure S2). These results a

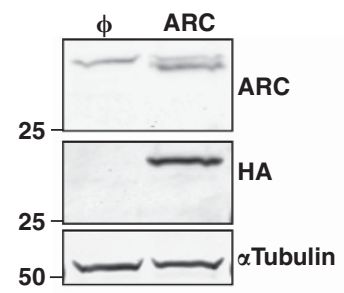

b Vehicle $\mathrm{TNF} \alpha+\mathrm{CHX} \quad \mathrm{TNF} \alpha$

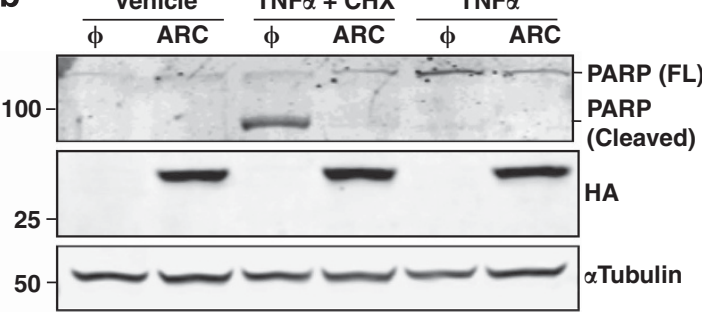

C
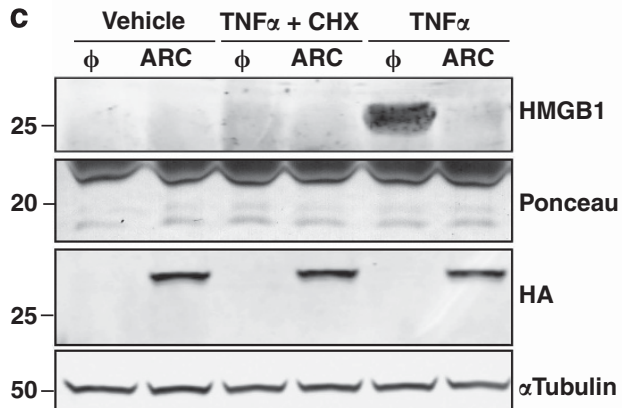

d

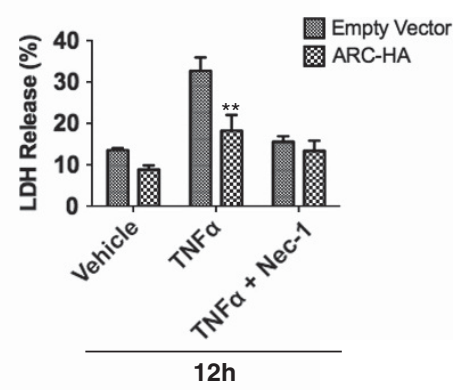

Figure 1 Overexpression of ARC suppresses TNF $\alpha$-induced programmed necrosis. (a) Immunoblot showing ARC levels in L929 cells stably transduced with empty vector ( $\Phi)$ or HA-tagged ARC (ARC). Endogenous ARC is the upper band, whereas the exogenous ARC is the lower band. (b) PARP cleavage is blocked by overexpression of ARC. Immunoblot showing PARP cleavage, a marker of apoptosis, in L929 cells stably transduced with empty vector ( $\Phi$ ) or HA-tagged ARC (ARC) in response to $6 \mathrm{~h}$ treatment with TNF $\alpha+$ CHX but not $12 \mathrm{~h}$ treatment of TNF $\alpha$ alone. (c) HMGB1 release is inhibited by overexpression of ARC. Immunoblot of media showing HMGB1 release, a marker of necrosis, following $12 \mathrm{~h}$ treatment of cells with TNF $\alpha$ alone but not $6 \mathrm{~h}$ treatment with TNF $\alpha+\mathrm{CHX}$. (d) TNF $\alpha$-induced LDH release, another marker of necrosis, is inhibited by ARC overexpression to a similar extent as that resulting from treatment with Nec-1, a potent inhibitor of RIP1 kinase activity and TNF $\alpha$-mediated necrosis. Data shown as mean \pm S.E., $n=4$. ${ }^{* *} P$-value $<0.005$ versus empty vector 
indicate that, as with apoptosis, the CARD is required for ARC to suppress TNF $\alpha$-induced necrosis.

\section{Endogenous levels of ARC suppress TNF $\alpha$-induced} necrosis in vitro and in vivo. To determine the physiological relevance of the preceding observations, we used RNAi to assess whether endogenous ARC blocks necrosis. L929 cell were depleted of ARC using stable expression of a short hairpin RNA (shRNA) (Figure 3A). A scrambled shRNA was used as control. Knockdown of ARC sensitized cells to TNF $\alpha$-induced necrosis, a result also observed using a
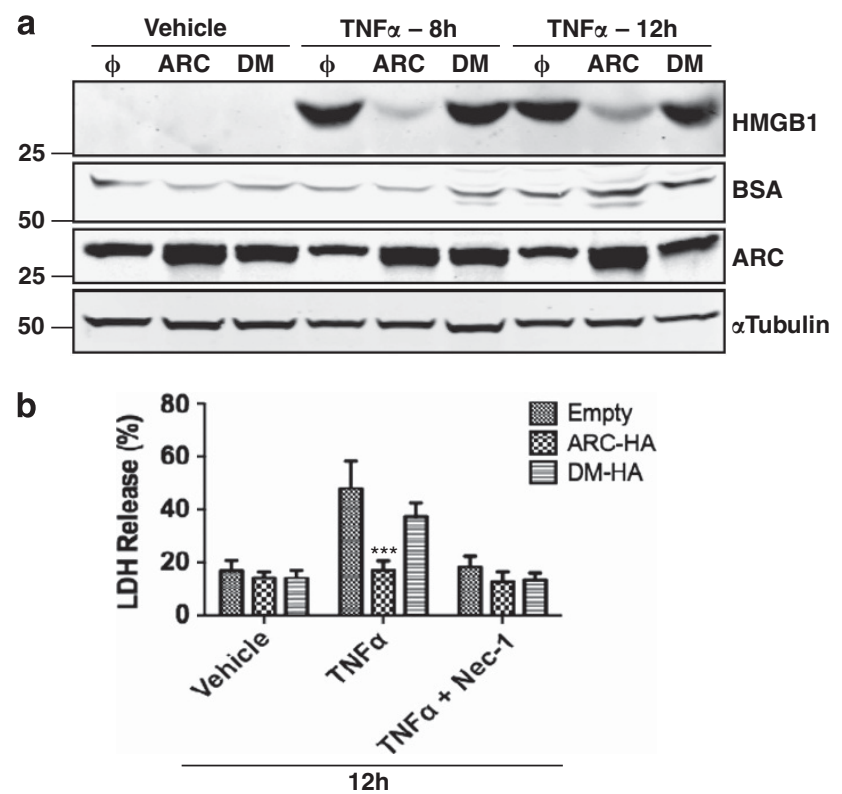

Figure 2 The ARC CARD is required for the ability of ARC to suppress TNF $\alpha$ induced necrosis. (a) Immunoblot showing inhibition of TNF $\alpha$-induced HMGB1 release by wild-type ARC but not by the CARD-defective double-point ARC mutant (L31F; G69R). L929 cells were stably transduced with empty vector (Ф), ARC-HA (ARC) or ARC-HA double-point CARD mutant (DM). Immunblot of bovine serum albumin (BSA) in media used as loading control. (b) Inhibition of TNF $\alpha$-induced LDH release by ARC requires the CARD. Data shown as mean \pm S.E. from $n=4$. ${ }^{* * *} P$-value $<0.001$ versus empty vector second hairpin (Figures $3 \mathrm{~A}$ and $\mathrm{B}$, and Supplementary Figure S3). Reconstitution of ARC knockdown in L929 cells with wild-type ARC, but not the ARC CARD mutant (DM), restored suppression of TNF $\alpha$-induced necrosis (Figure $3 C$ ). Similarly, knockdown of ARC increased TNF $\alpha$-induced necrosis in MCF7 cells that were rendered competent to undergo necroptosis through RIP3 transfection (Supplementary Figure S4). Collectively, these data demonstrate that endogenous levels of ARC inhibit TNF $\alpha$-induced necrosis.

Infection of mice with vaccinia virus induces necrotic cell death through a pathway mediated by TNF $\alpha .{ }^{12}$ We used this model to test whether ARC also limits necrosis in vivo. To assess the role of endogenous ARC, wild-type mice were compared with knockout mice with generalized absence of ARC, which we had previously generated. ${ }^{29}$ Three days following administration of vaccinia virus, mice lacking ARC exhibited markedly increased necrosis and mononuclear cell infiltration in adipose tissue compared with wild-type controls (Figures 3D and E). As an additional control, we examined the liver, a tissue in which ARC levels are low even in wild-type mice. ${ }^{19}$ As would be expected, liver necrosis resulting from vaccinia virus infection was similar in mice lacking $A R C$ and wild-type controls (Figure 3F). These data demonstrate that endogenous ARC suppresses necrosis and inflammation elicited by vaccinia virus infection.

To further establish the specificity of the inhibitory role of $A R C$ in the TNF $\alpha$ pathway, we used TNF $\alpha$-induced systemic inflammatory response, another in vivo model. This syndrome had been shown to cause lethality driven by RIP1- and RIP3-dependent TNF $\alpha$-induced necrosis. ${ }^{30}$ As ARC suppresses TNF $\alpha$-induced necrosis, we expected that the depletion of ARC would worsen TNF $\alpha$-induced systemic inflammatory response. Wild-type mice and mice deficient in ARC expression were injected intravenously with $500 \mu \mathrm{g} / \mathrm{kg}$ body weight of $\mathrm{TNF} \alpha$ followed by monitoring of body temperature and survival. The body temperatures of wildtype mice dropped as expected after TNF $\alpha$ injection and a substantial proportion of these mice died within $24 \mathrm{~h}$ (Figure 3G). However, TNF $\alpha$ injection resulted in a more rapid drop in body temperature and shorter time-to-death in mice lacking ARC (Figure 3G). These observations indicate

Figure 3 Endogenous levels of ARC suppresses TNF $\alpha$-induced necrosis. (A) Immunoblot showing that TNF $\alpha$-induced HMGB1 release is increased in L929 cells with stable ARC knockdown. Cells were treated with TNF $\alpha$ + Nec-1 for $10 \mathrm{~h}$.Scr, scrambled control; KD, ARC shRNA knockdown; Nec-1, necrostatin-1. (B) TNF $\alpha$-induced LDH release is increased by ARC knockdown in L929 cells. Data shown as mean \pm S.E. from $n=3$. ${ }^{* \star}{ }^{*} P$-value $<0.001$ versus scrambled control. (C) TNF $\alpha$-induced LDH release is restored to baseline levels by reconstitution of ARC knockdown cells with wild-type (WT) ARC, but not the CARD mutant (DM). Mean \pm S.E. from $n=7$ are shown. ${ }^{* * *} P$-value $<0.001 \mathrm{KD}$ :Empty versus Scr:Empty. ${ }^{\#} P$-value $<0.001 \mathrm{KD}: A R C$-HA compared with KD:Empty. Scr:Empty, scrambled shRNA + empty vector; KD:Empty, ARC shRNA + empty vector; KD:ARC-HA, ARC shRNA + WT ARC-HA; KD:DM-HA, ARC shRNA + ARC CARD double mutant (DM-HA). (D) Endogenous ARC suppresses necrosis in visceral fat resulting from vaccinia virus infection in vivo. Representative micrographs showing H\&E staining of visceral fat from WT mice and mice lacking ARC (KO). Panels $c$ and $f$ are increased magnifications of the boxed areas in panels $b$ and e, respectively. Bar $=200 \mu \mathrm{m}$ for panels $a, b, d, a n d e ; 50 \mu \mathrm{m}$ for panels $c$ and $f$. Arrowheads point to fatty tissue necrotic areas containing inflammatory cells. (E) Quantification of percentage of necrotic areas in fat tissue from WT and KO mice. Using ImageJ, percentage of necrotic area was determined in $\geq 90$ fields per genotype ( $\geq 9$ fields per mouse $\times 10$ mice for each genotype. ${ }^{\star \star} P$-value $<0.005$ versus WT. (F) Representative micrographs showing H\&E staining of liver tissue from WT and KO mice. Arrowheads point to focal clusters of inflammatory cells. Contrary to the adipose tissue, absence of ARC does not affect necrosis in the liver infected with vaccinia virus, as ARC is expressed at none to low levels in the livers of WT mice. Bar $=100 \mu \mathrm{m}$. (G) Endogenous ARC suppresses TNF $\alpha$-induced systemic inflammatory response syndrome. Rectal body temperature and survival of WT mice and mice lacking ARC (KO) injected intravenous with either recombinant mouse TNF $\alpha 500 \mu \mathrm{g} / \mathrm{kg}$ body weight or equivalent volume of phosphate-buffered saline (PBS). Time refers to after TNF $\alpha$ injection. Data shown as mean \pm S.E. WT-PBS $(n=8), \mathrm{KO}$-PBS $(n=8)$, WT-TNF $\alpha(n=11), \mathrm{KO}-\mathrm{TNF} \alpha(n=11)$. Body temperatures were monitored, and mice with a temperature $<22{ }^{\circ} \mathrm{C}$ were euthanized for ethical reasons and were considered dead. Statistics could only be performed up to $6 \mathrm{~h}$ post injection due to attrition (see Materials and Methods). Repeated measures two-way analysis of variance was used to compare body temperatures between ARC-deficient mice and WT mice injected with TNF $\alpha$. ${ }^{* * \star} P$-value $<0.0001$ refers to differences between the entire curves, not at a single time point. A Kaplan-Meier curve was used to analyze KO injected with TNF $\alpha$ versus WT injected with TNF $\alpha$ survival curves. ${ }^{*} P$-value $<0.05$ 


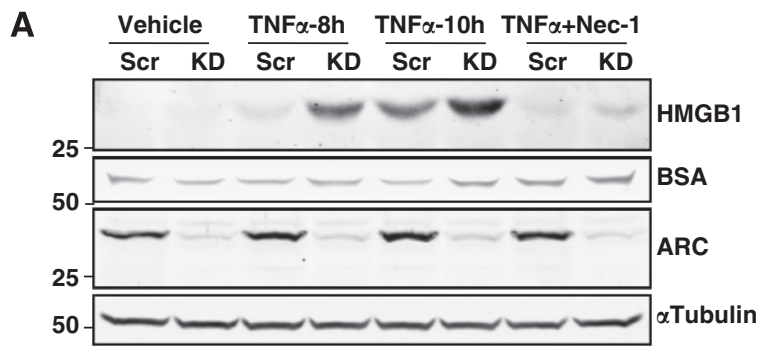

B

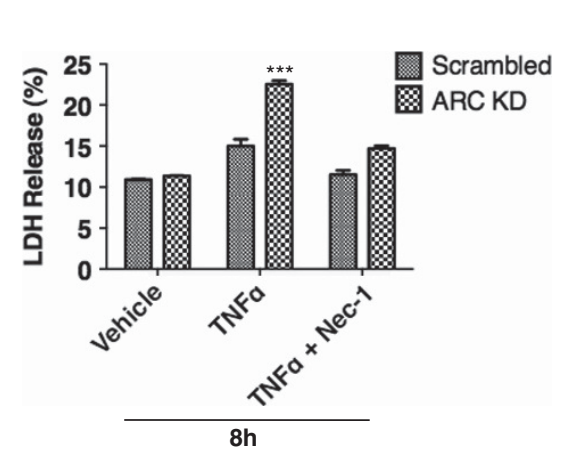

C

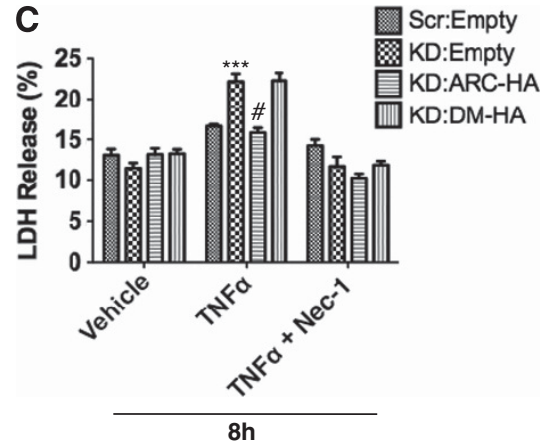

D

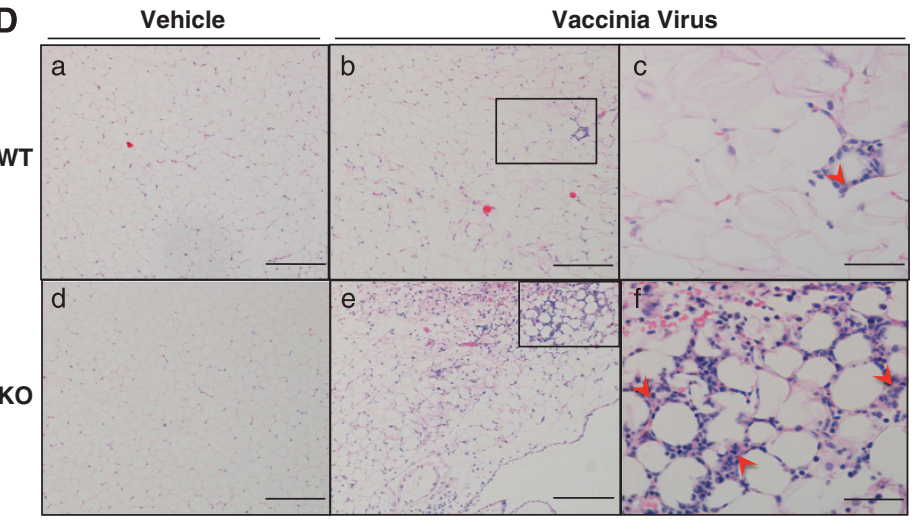

E

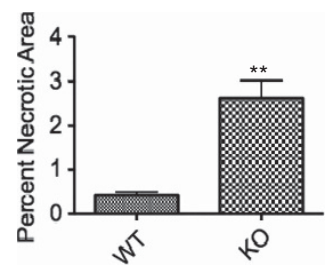

$\mathbf{F}$
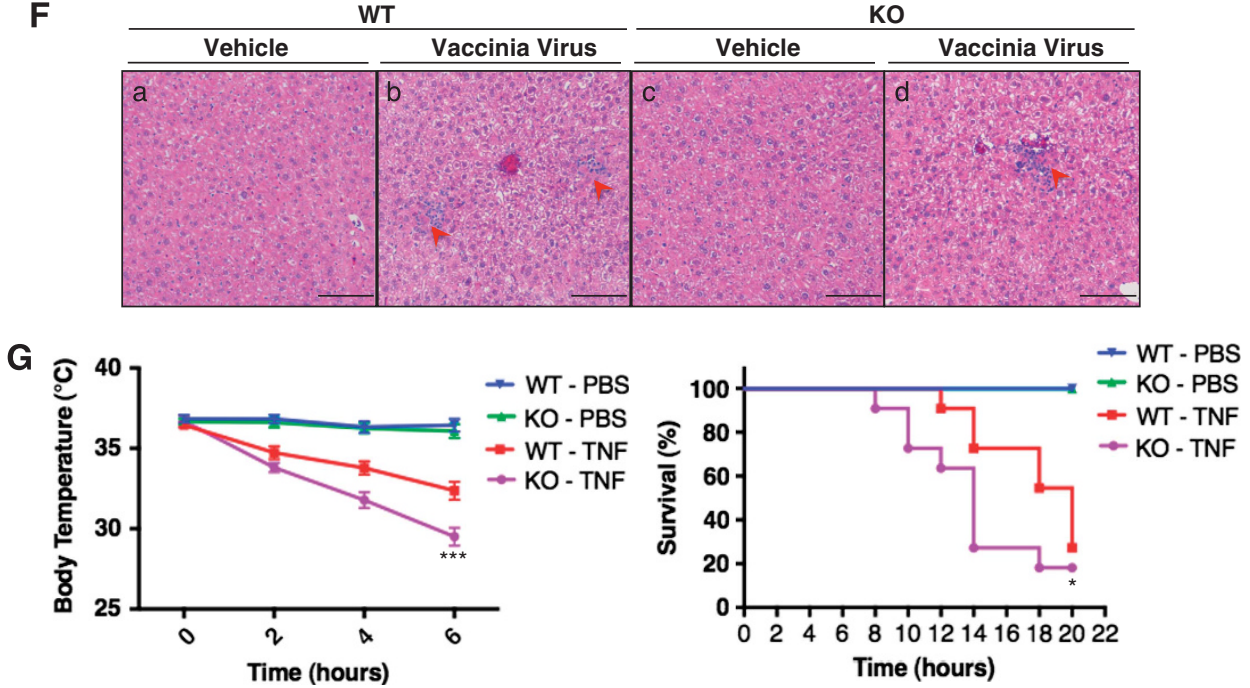


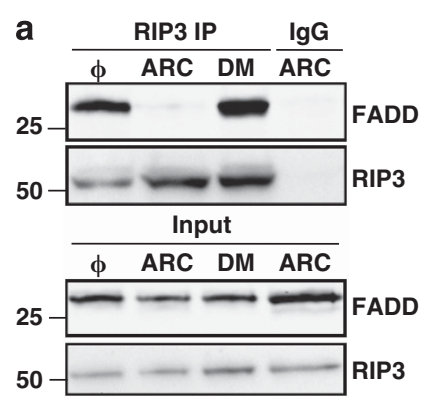

b

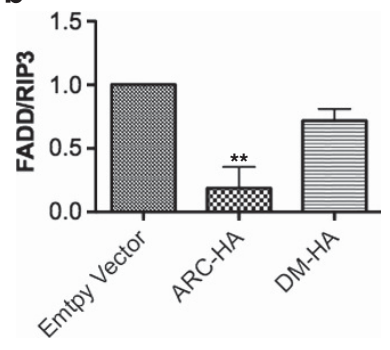

C

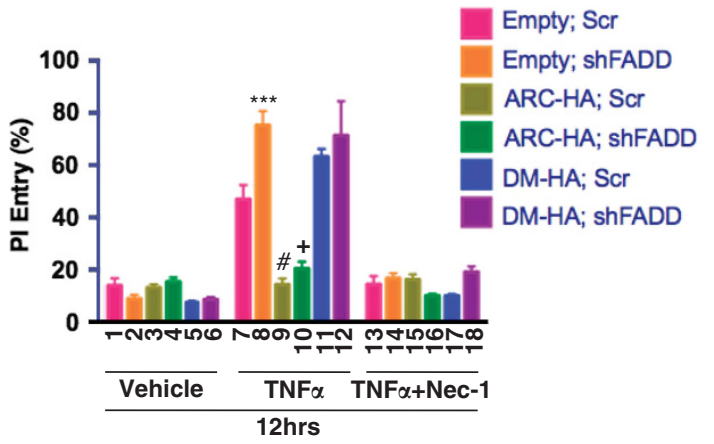

Figure 4 ARC inhibits TNF $\alpha$-induced necrosis independently of FADD. (a) RIP3 immunoprecipitation was performed in fractions isolated from size exclusion chromatography in which RIP3, FADD, and ARC co-elute using L929 cells stably transfected with empty vector $(\Phi)$, ARC-HA, or the CARD-defective double-point mutant ARC (DM-HA). (b) Densitometry quantification of FADD immunoprecpitated with RIP3 represented as a ratio of FADD detected over the densitometric amount of RIP3 detected. Quantitative data represented as mean \pm S.E. from $n=3$. ${ }^{* *} P$-value $<0.005$ versus empty vector. (c) ARC inhibits TNF $\alpha$-induced necrosis independently of FADD. PI entry into cells treated with vehicle, TNF $\alpha$, or TNF $\alpha+$ necrostatin-1 (Nec-1) for $12 \mathrm{~h}$. Note that ARC suppresses TNF $\alpha$-induced PI entry as effectively in cells in which FADD is present or depleted (bar 9 versus bar 10 , $P$-value $=$ NS (not significant)). Data shown represent mean \pm S.E. from $n=5$. ${ }^{* * *} P$-value $<0.001$ bar 7 versus bar 8 ; ${ }^{\#} P$-value $<0.0001$ bar 7 versus bar 9 ; ${ }^{+} P$-value $<0.001$ bar 7 versus bar 10

that endogenous ARC has a role in regulating $\mathrm{TNF} \alpha$-induced lethality in vivo.

\section{ARC-FADD interaction is dispensable for suppression} of TNF $\alpha$-induced necrosis by ARC. As the CARD is required for ARC to suppress TNF $\alpha$-induced necrosis, we hypothesized that this inhibition involves an interaction of ARC with a death-fold motif-containing protein shared by both the TNF $\alpha$-induced apoptosis and necrosis pathways. FADD is present in complex II of the TNF $\alpha$ signaling pathway, ${ }^{9}$ and as noted above, ARC binds FADD directly through an interaction mediated by the ARC CARD and FADD DD. ${ }^{20}$ Furthermore, FADD exists constitutively in complex with RIP3, a critical activator of regulated necrosis. ${ }^{12}$ Thus, we postulated that ARC inhibits both apoptosis and necrosis at complex II through a mechanism involving the sequestration of FADD.

As we have shown in other cell types, ${ }^{20}$ we confirmed that ARC interacts with FADD in a CARD-dependent manner in L929 cells under basal and TNF $\alpha$-treated conditions (data not shown). Next, we performed size exclusion fast protein liquid chromatography on whole cell lysates from these stable cell lines to identify fractions in which FADD and RIP3 co-elute and used these fractions to assess whether ARC disrupts the
FADD-RIP3 complex. Overexpression of wild-type ARC markedly decreased the amount of FADD in complex with RIP3 (Figures $4 a$ and b). In contrast, this complex was unaffected by CARD-defective ARC. These data suggest that disruption of the FADD-RIP3 interaction may mediate inhibition of necrosis by ARC.

To further examine the functional significance of ARC binding to FADD and disrupting the FADD-RIP3 complex, we depleted cells of FADD using shRNA. If sequestration of FADD by ARC is important for inhibition of TNF $\alpha$-induced necrosis, one would predict that knockdown of FADD would phenocopy overexpression of ARC. In fact, the ability of ARC to suppress necrosis was not affected by FADD knockdown (Figure 4c, bar 10 versus bar 9). Our data also confirmed that necrosis is exacerbated by depletion of FADD (Figure 4c, bar 8 versus bar 7), consistent with previous work, ${ }^{31}$ possibly due to decreased caspase-8 activation. ${ }^{9}$ Thus, despite disruption of the FADD-RIP3 interaction by ARC overexpression, we conclude that the ability of ARC to suppress necrosis is independent of FADD.

ARC interacts with TNFR1 to suppress TNF $\alpha$-induced necrosis. Other death-fold-containing proteins reside in the $\mathrm{TNF} \alpha$ signaling pathway upstream of both necrosis and apoptosis. These include TNFR1, TRADD, and RIP1, constituents of complex I in this pathway. As complex I also mediates TNF $\alpha$-induced NF- $\kappa B$ signaling, ${ }^{9}$ we used activation of NF- $\kappa$ B as a readout to examine the effect of ARC on the formation of this complex. Upon TNF $\alpha$-stimulation, NF- $\kappa \mathrm{B}$ translocates from cytosol to nucleus where it transactivates its target genes. We assessed the abundance of p65, a component of NF- $\kappa \mathrm{B}$, in nuclear extracts using an enzymelinked immunosorbent assay (ELISA) that quantifies the binding of $\mathrm{p} 65$ to an NF- $\kappa$ B DNA consensus site. Levels of p65 increased in the nucleus in response to TNF $\alpha$ treatment (Figure 5a). In contrast, TNF $\alpha$-induced nuclear translocation of p65 was suppressed by stable expression of wild-type ARC but not by the CARD mutant (DM) (Figure 5a). Conversely, knockdown of ARC increased the abundance of p65 in the nucleus in response to TNF $\alpha$ treatment (Figure 6a). To further confirm these observations, we also assessed expression of several NF- $\kappa \mathrm{B}$ target genes using real-time PCR. Overexpression of wild-type ARC, but not the CARD mutant (DM), reduced mRNA levels of Bcl-xL, IL-6, FLIP, iNOS, and TRAF2 in response to TNF $\alpha$ treatment (Figures $5 b-f$ ). Moreover, knockdown of ARC increased the expression of these genes (Figures 6b-f). Taken together, these data indicate that ARC inhibits TNF $\alpha$-induced NF- $\kappa$ B activation in a CARD-dependent manner.

These findings also suggest a mechanism by which ARC suppresses TNF $\alpha$-induced necrosis at the level of complex I. To understand the molecular basis, we considered that the ARC CARD and the DDs of Fas and FADD have been shown to interact directly. ${ }^{20}$ TNFR1, TRADD, and RIP1 all possess DDs, but we have previously demonstrated that ARC does not interact with TRADD and RIP1. ${ }^{20}$ Accordingly, we focused on TNFR1. As antibodies to immunoprecipitate human TNFR1 are considerably better than those available for the mouse, we used human Jurkat cells, another well-characterized model of TNF $\alpha$-induced necrosis. ${ }^{12,32,33}$ Using Jurkat 

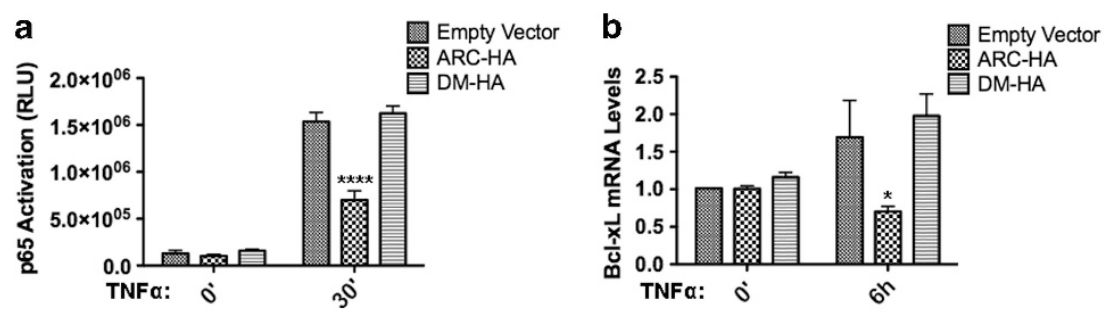

C

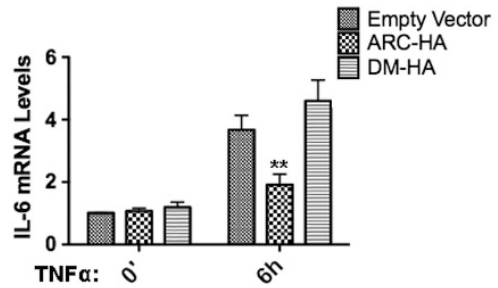

e

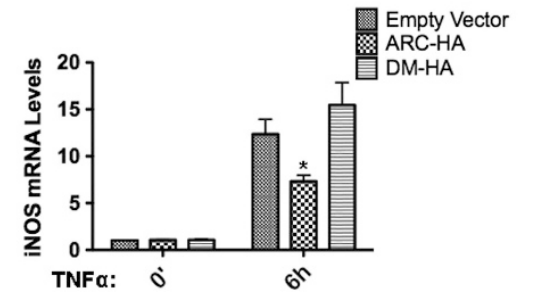

d
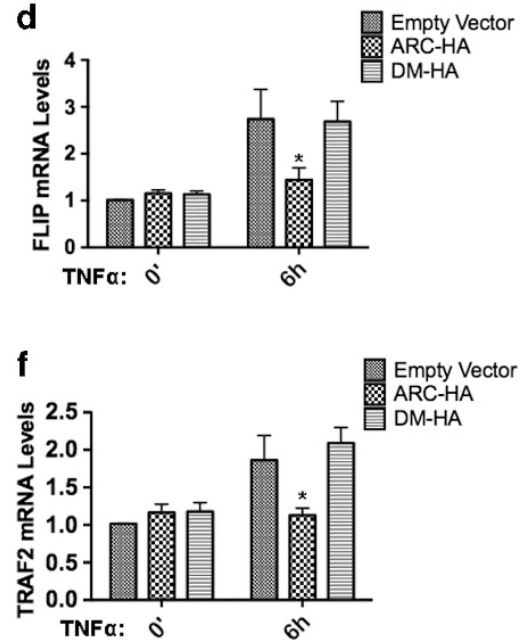

Figure 5 ARC inhibits TNF $\alpha$-induced NF- $\kappa$ B activation in a CARD-dependent manner. (a) The abundance of p65 in nuclear extracts was quantified using an ELISA that detects $p 65$ binding to its DNA consensus sequence. Nuclear fractions were obtained from TNF $\alpha$-treated L929 cells stably transduced with empty vector ( $\Phi)$, ARC-HA, or ARC CARD mutant-HA (DM-HA). Data shown as mean \pm S.E. from $n=3$. ${ }^{* \star * *} P$-value $<0.0001$ versus empty vector. $(\mathbf{b}-\mathrm{f})$ Levels of NF- $\kappa$ B target gene transcripts normalized to those of $18 \mathrm{~S}$ in the same cell lines as in panel a as determined by quantitative real-time PCR using transcript-specific primers. Data shown as mean $\pm \mathrm{S}$.E. $N=3$ in panels $\mathbf{b}, \mathbf{e}$ and $\mathbf{f} ; n=7$ in panels $\mathbf{c}$ and $\mathbf{d}$. ${ }^{*} P$-value $<0.05$ compared with empty vector; ${ }^{* *} P$-values $<0.01$ versus empty vector. FLIP, FLICE-like inhibitory protein; IL, interleukin; iNOS, inducible nitric oxide synthase; RLU, relative luminescence unit

cells stably transfected with ARC-HA, we observed an interaction between ARC and TNFR1 (Figure 7a). Immunoprecipitations using purified recombinant $A R C$ and the intracellular domain of TNFR1 demonstrated that this interaction is direct (Figure 7b). The inhibition of TNF $\alpha$ induced necrosis by ARC overexpression was similar in magnitude to that observed by blocking TNFR1 using a neutralizing antibody or by knocking down TNFR1 with small interfering RNA (siRNA) (Figures 7c and d, bar 8 versus bar 9). In addition, knockdown or antagonism of TNFR1 rescued the increase in TNF $\alpha$-induced necrosis resulting from $A R C$ knockdown (Figures 7e and f), consistent with the interaction between ARC and TNFR1 being functionally important.

Activation of TNFR1 in this pathway next recruits TRADD. Yet, previous work has shown that TRADD is not essential for necrosis induced by $T N F \alpha$, because RIP1 can be recruited to TNFR1 even in the absence of TRADD. ${ }^{33}$ Indeed, we observed that cells depleted of TRADD are still able to undergo TNF $\alpha$-induced necrosis, which is blocked by ARC (Supplementary Figure S5). In contrast, RIP1 is essential for TNF $\alpha$-induced necrosis. ${ }^{12,31,33}$ Therefore to assess the functional consequences of ARC-TNFR1 binding, we tested whether this interaction disrupts the recruitment of RIP1 upon TNF $\alpha$ stimulation. Indeed, overexpression of ARC decreased the amount of RIP1 that immunoprecipitates with TNFR1 in response to TNF $\alpha$ stimulation (Figure $7 \mathrm{~g}$ ). Conversely, knockdown of endogenous ARC increased RIP1 recruitment to TNFR1 (Figure 7h). Taken together, these data indicate that $A R C$ inhibits $T N F \alpha$ signaling by interacting with TNFR1 to prevent the recruitment of RIP1 to complex I, thereby abrogating TNF $\alpha$-induced necrosis (Supplementary Figure S6).

\section{Discussion}

Although most endogenous inhibitors of apoptosis function in a circumscribed manner to suppress either mitochondrial or death receptor apoptosis signaling, ARC has the unusual property of inhibiting both pathways. ${ }^{20}$ The major new finding in this study is that ARC also suppresses TNF $\alpha$-induced regulated necrosis. This observation is explained by our finding that ARC acts at the level of TNFR1 to interfere with the recruitment of RIP1 into complex I, thereby inhibiting both forms of cell death as well as TNF $\alpha$-induced NF- $\kappa$ B activation. Modulation of $\operatorname{TNF} \alpha$ signaling by $A R C$ was demonstrated using both gain- and loss-of-function approaches, the latter indicating that physiological levels of ARC are important in this regulation. These results translate to the in vivo setting where deletion of $\mathrm{ARC}$ exacerbates necrotic tissue damage resulting from vaccinia virus infection and TNF $\alpha$-induced systemic inflammatory response syndrome.

We initially postulated that ARC inhibits both apoptosis and necrosis at complex II through a mechanism involving the 

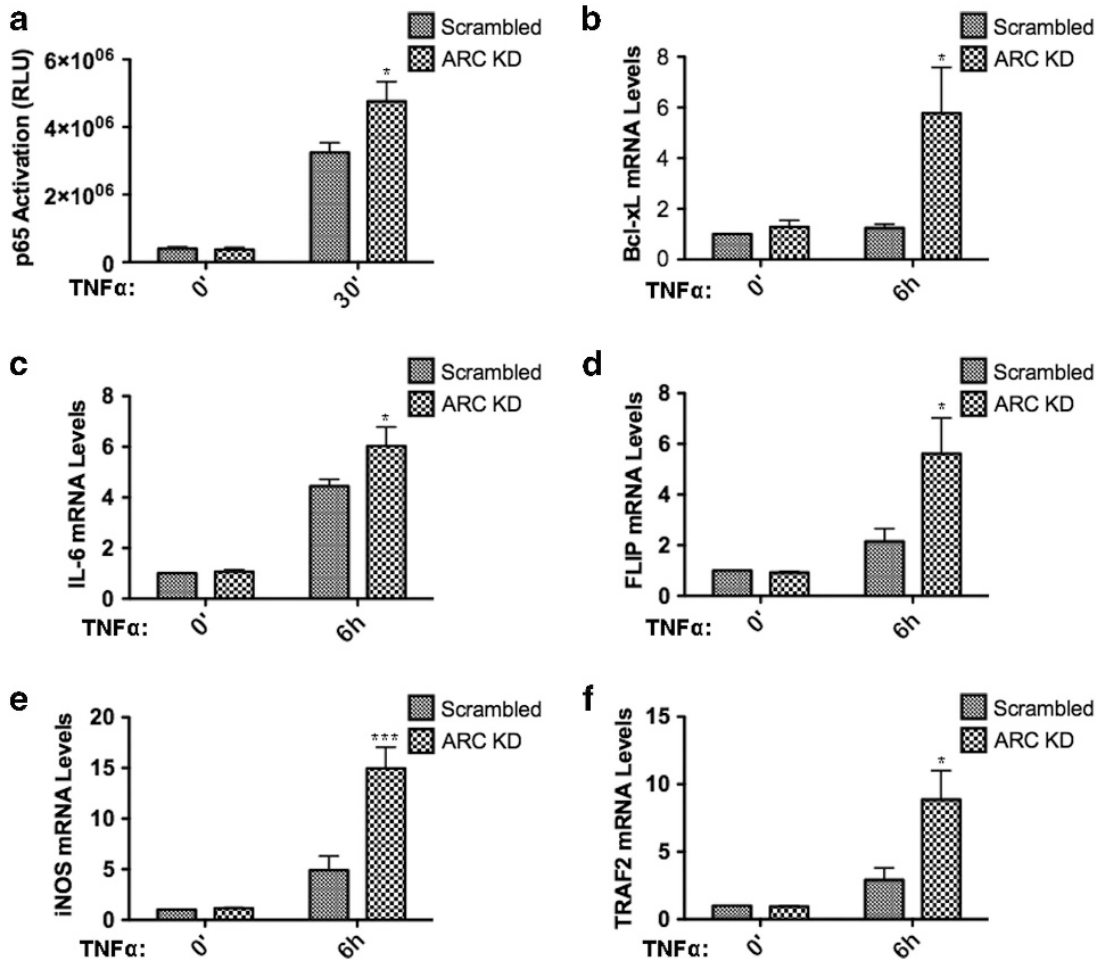

Figure 6 The knockdown of ARC increased TNF $\alpha$-induced NF- $\kappa$ B activation. (a) L929 cells stably transduced with scrambled shRNA control (Scr) or ARC shRNA (ARC $\mathrm{KD}$ ) were subjected to TNF $\alpha$ treatments, and p65 abundance in nuclear extracts was quantified using ELISA. Mean $\pm \mathrm{S}$.E. from $n=3$ are shown. ${ }^{*} P$-value $<0.05$ versus scrambled control. (b-f) Levels of NF- $\kappa$ B target gene transcripts normalized to those of $18 \mathrm{~S}$ in the same cell lines as in panel a as determined by quantitative real-time PCR using transcript-specific primers. Data shown as mean \pm S.E. from $n=3$. ${ }^{*} P$-value $<0.05$; ${ }^{* * *} P$-values $<0.001$, compared with scrambled control. FLIP, FLICE-like inhibitory protein; IL, interleukin; iNOS, inducible nitric oxide synthase; RLU, relative luminescence unit

sequestration of FADD. The rationale was based on three components: the known interaction between ARC and FADD; ${ }^{20}$ the fact that FADD recruitment to complex II is required for the subsequent recruitment and activation of procaspase-8 to initiate apoptosis; ${ }^{9}$ and the fact that FADD is constitutively in complex with RIP3, a kinase indispensable for necrosis in the death receptor pathway. ${ }^{12}$ However, despite the disruption of FADD-RIP3 binding by ARC overexpression, our FADD knockdown studies demonstrated that inhibition of necrosis by ARC is independent of FADD. These observations directed our attention to complex I, in which reside other death-fold-containing proteins, which would be likely targets for ARC binding. In fact, we found that ARC binds TNFR1, thereby decreasing RIP1 recruitment. Thus, combined inhibition of necrosis and apoptosis by ARC reflects its interference with complex I, which is common to both death processes. In support of this model, ARC also inhibits NF- $\kappa$ B activation, which takes place downstream of TNFR1.

TNF $\alpha$ activates cell survival, as well as cell death, pathways. ${ }^{3}$ Therefore, inhibition of TNF $\alpha$ signaling engenders an interesting question. In the absence of TNF $\alpha$-induced cell survival and death signals, does the cell live or die? Although multiple signals impact this decision, our observation that disruption of $\mathrm{TNF} \alpha$ signaling in some cell types results in survival in response to TNF $\alpha$ treatment suggests that inhibition of death signaling compensates for loss-of-survival mechanisms in these cellular contexts. This concept is concordant with studies showing that deletion of TNF $\alpha$ or
TNFR1 can rescue the massive liver cell death and embryonic lethality induced by deletion of RelA, a critical subunit of $\mathrm{NF}-\kappa \mathrm{B}^{34-36}$

Overexpression of ARC has previously been shown to rescue acetaminophen-induced hepatocyte necrosis in vivo. ${ }^{37}$ However, studies using TNF $\alpha$-neutralizing antibody and TNFR1 knockout mice indicate that cell killing in the acetaminophen model occurs independently of TNF $\alpha$ signaling. ${ }^{38,39}$ In contrast, our study demonstrates a novel action of ARC to inhibit the TNF $\alpha$ pathway itself to block multiple downstream outcomes, including apoptosis, necrosis, and NF- $\kappa$ B activation. Moreover, the use of loss-of-function, as well as gain-of-function, approaches in the current study indicate that the TNF $\alpha$ axis is regulated by physiological levels of ARC as well as ARC overexpression.

The fact that ARC suppresses both apoptosis and necrosis may have important implications for diseases, such as myocardial infarction and stroke, ${ }^{40}$ in which both forms of cell death have important roles. In fact, at baseline ARC is abundant in both cardiomyocytes and neurons, ${ }^{18,41}$ but its ability to protect these cells is undercut by its rapid proteasomal degradation in response to ischemic death signals. ${ }^{42,43}$ Accordingly, pharmacological strategies to blunt ARC degradation may provide novel therapies to inhibit both apoptosis and necrosis, thereby maintaining tissue viability and function in these important ischemic syndromes. Conversely, the presence of ARC may prove to be detrimental for the treatment of cancer. Necrotic phenotypes are often seen 
a
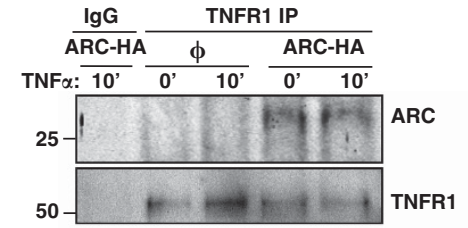

$$
\text { Input }
$$

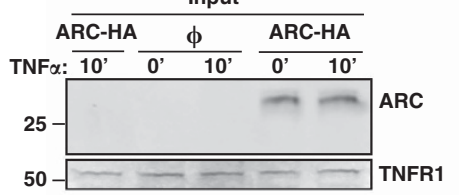

C

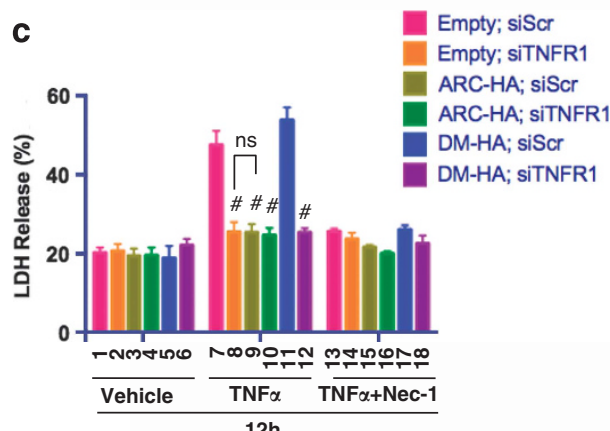

e

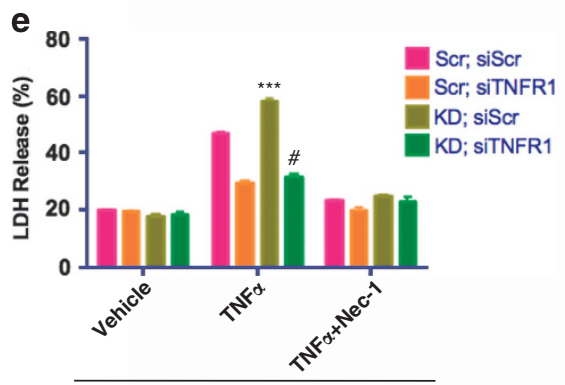

g

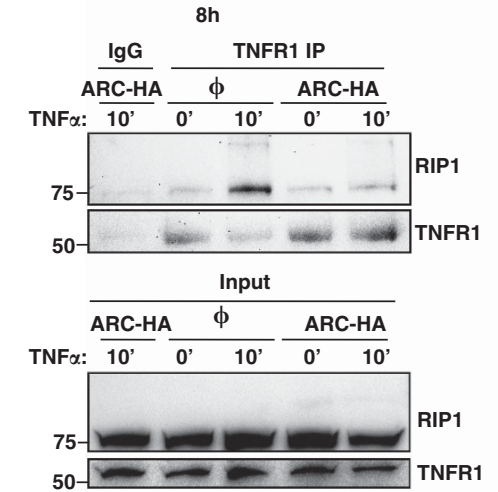

h b

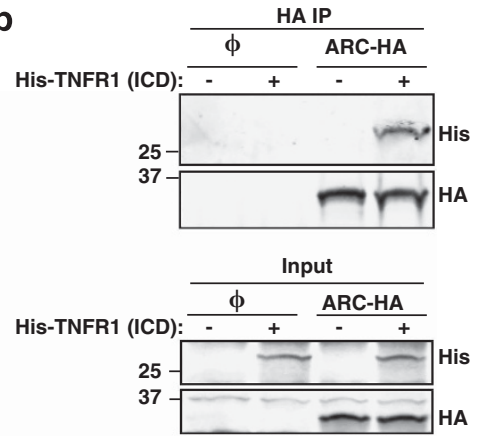

d

Empty; Vehicle

Empty; TNFR1 antagonist

ARC; Vehicle

ARC; TNFR1 antagonist

DM; Vehicle
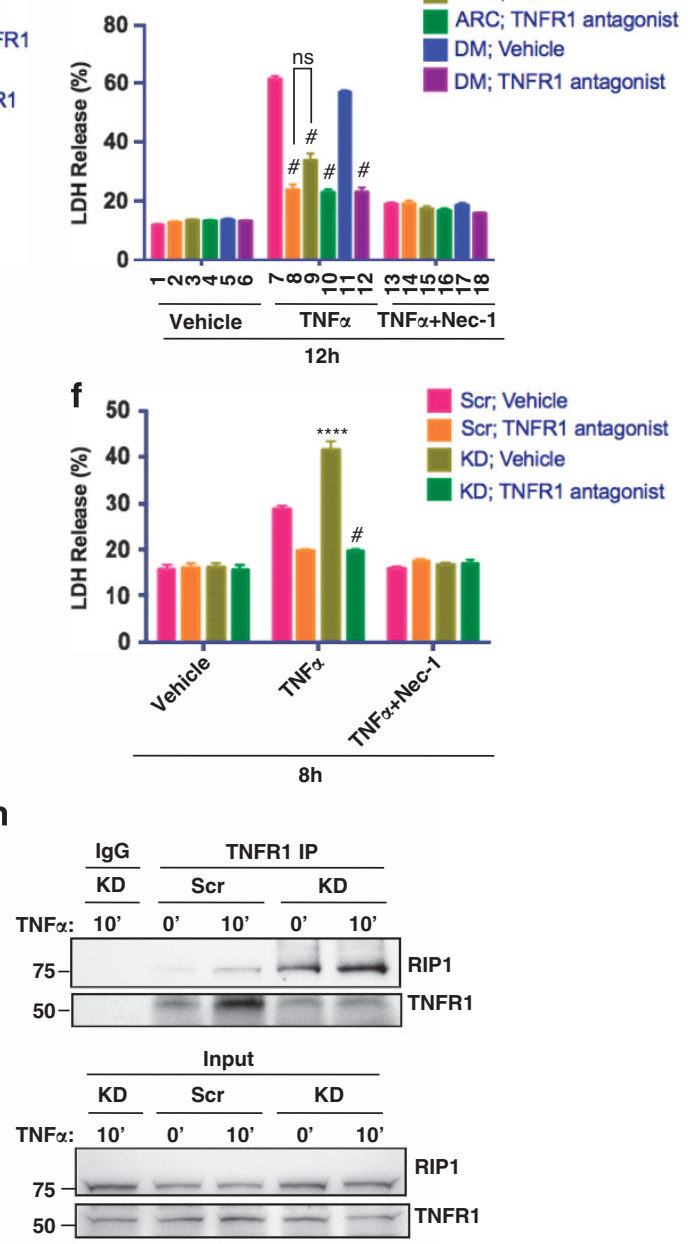

Figure 7 ARC interacts with TNFR1 to inhibit TNF $\alpha$-induced necrosis. (a) Immunoprecipitation (IP) of TNFR1 in lysates of TNF $\alpha$-stimulated Jurkat cells stably transfected with empty vector $(\Phi)$ or ARC-HA. Immunoprecipitates were resolved by sodium dodecyl sulfate-polyacrylamide gel electrophoresis (SDS-PAGE) and immunoblotted for ARC and TNFR1. Control IP performed with immunoglobulin G (IgG). Input lanes shown below IP. (b) Recombinant ARC-HA was mixed with recombinant His-TNFR1 intracellular domain (ICD). IP performed with the HA-conjugated agarose beads, immunoprecipitates were resolved by SDS-PAGE and immunoblotted for His and HA. TNF $\alpha$-induced LDH release is inhibited by transient knockdown of TNFR1 with siRNA (c) or co-treatment with TNFR1 antagonist (d) to a similar extent as ARC overexpression (bar 8 versus bar 9 , $P$-value $=$ NS (not significant)). siScr, control siRNA; siTNFR1, siRNA targeting TNFR1. Data shown as mean \pm S.E. from $n=3$. ${ }^{\#} P$-value $<0.0001$ as compared with cells transfected with empty vector and control siRNA (Emtpy; siScr) or transfected with empty vector and co-treated with vehicle (Emtpy; Vehicle). Transient knockdown of TNFR1 (e) or co-treatment with TNFR1 antagonist (f) rescues TNF $\alpha$-induced LDH release in ARC knockdown L929 cells. Data shown as mean \pm S.E. from $n=3$. ${ }^{* \star *} P$-value $<0.0001$ as compared with cells transduced with scrambled shRNA (Scr) and transfected with control siRNA (Scr; siScr) or transduced with scrambled shRNA and co-treated with vehicle (Scr; Vehicle). ${ }^{\#}$ P-value $<0.0001$ versus cells transduced with shRNA targeting ARC and transfected with control siRNA (KD; siScr) or transduced with shRNA targeting ARC and co-treated with vehicle (KD; Vehicle). (g) ARC overexpression disrupts TNF $\alpha$-induced association of RIP1 with TNFR1. IP of TNFR1 in TNF $\alpha$-stimulated Jurkat cells stably transduced with empty vector $(\Phi)$ or ARC-HA, followed by immublotting for RIP1 and TNFR1. (h) Knockdown of ARC increases the association of RIP1 with TNFR1. IP of TNFR1 in TNF $\alpha$-stimulated Jurkat cells stably transduced with scrambled shRNA (Scr) or ARC shRNA (KD), followed by immunoblotting for RIP1 and TNFR1 
in cancer treated with chemotherapies or radiotherapies. ${ }^{44-46}$ Thus, it has been suggested that the induction of death receptor-mediated necrosis could be used to target apoptosisresistant cancer cells. ${ }^{46,47}$ Increased ARC expression levels has been observed in diverse cancers, including pancreatic, breast, and lung cancers, as well as glioblastoma and lymphoma. ${ }^{19,29,48-50}$ Therefore, as ARC suppresses both apoptosis and necrosis, the presence of ARC can render cancer cells resistant to chemotherapy and radiotherapy. Accordingly, mechanisms that inhibit ARC or induce its degradation may be useful as therapeutic strategies to effectively stimulate cell death in cancers.

\section{Materials and Methods}

Cell lines, plasmids, and recombinant proteins. L929, Jurkat, and MCF7 cell lines were purchased from ATCC (Manassas, VA, USA) and cultured as instructed by ATCC. RIP3 CDNA was amplified by RT-PCR from total RNA of Jurkat cells and then cloned into pcDNA3.1 plasmid. HA-tagged wild-type human ARC and the corresponding CARD double mutant (L31F; G69R) (DM) in pBABE vector are as described. ${ }^{42,48}$ Recombinant retroviruses were generated, and L929 cells were transduced as described. ${ }^{51}$ Jurkat cells were transfected with HAtagged human ARC in pcDNA3.1 using Cell Line Nucleofector Kit V (Lonza, Allendale, NJ, USA). Lentivirus harboring MISSION shRNAs in the pLKO.1 backbone (Sigma, St. Louis, MO, USA) were used for knockdown studies: shRNA mouse ARC coding region (TRCN000086914), shRNA mouse ARC coding region (TRCN000086915), shRNA human ARC 3' UTR (TRCN0000118447), shRNA mouse FADD coding region (TRCN0000012285), and scrambled shRNA for both mouse and human (SHCO02V). Transient knockdown of TNFR1 in L929 cells was done using Trilencer-27 siRNA knockdown duplexes against TNFR1 from OriGene (Rockville, MD, USA). Transient knockdown of TRADD in L929 cells was performed using SMARTpool siRNA reagent (Thermo Scientific, Pittisburgh, PA, USA). Full length, wild-type ARC-HA protein was made in vitro transcription/ translation system as described (TNT kit; Promega, Madison, WI, USA) and purified through pull-down with anti-HA-conjugated agarose beads. His-tagged recombinant intracellular domain (residues 204-455) of the TNFR1 protein was produced in BL21 Escherichia coli as His-fusion protein and purified on nickel-
\end{abstract} charged nitrilotriacetic acid agarose (Thermo Scientific, Rockford, IL, USA).

Antibodies and reagents. Primary antibodies include: ARC (Cayman Chemical, Ann Arbor, MI, USA); $\beta$-actin (Sigma-Aldrich, St. Louis, MO, USA); HA (Roche Applied Science, Indianapolis, IN, USA); BSA, HMGB1, His (Abcam, Cambridge, MA, USA); histone H3, PARP, p65 (Cell Signaling Technology, Danvers, MA, USA); RhoGDl $\alpha$ (A-20) (Santa Cruz Biotechnology, Dallas, TX, USA); mouse RIP3 (Prosci, Poway, CA, USA); human RIP3 (Thermo Scientific); RIP1 (BD Biosciences, San Jose, CA, USA); and FADD (Enzo Life Sciences, Farmingdale, NY, USA). Secondary antibodies include: goat $\alpha$-mouse and goat $\alpha$-rabbit (Li-COR, Lincoln, NE, USA), and goat-anti-rat Alexa Fluor 680 (Molecular Probes, Invitrogen, Grand Island, NY, USA). Human TNFR1 was immunoprecipitated with antibody from R\&D Systems (Minneapolis, MN, USA) and immunoblotted with antibody from Abcam. Ponceau S solution was obtained from Sigma-Aldrich. TNFR1 antagonist was a monoclonal antibody against mouse TNFR1 from R\&D Systems (MAB430).

Immunoprecipitations and immunoblottings. Cell lysates were prepared and immunoprecipitated as described previously, ${ }^{12}$ except for $0.1 \%$ (v/v) NP-40. Signals were detected using ODYSSEY Infrared Imaging Systems (Li-COR). For human TNFR1 immunoprecipitations, lysis was carried out in $1 \%$ (v/v) NP-40, $20 \mathrm{mM}$ Tris-Cl pH 7.0, $150 \mathrm{mM} \mathrm{NaCl}, 1 \mathrm{mM}$ EDTA, $1 \mathrm{mM}$ $\beta$-glycerolphosphate, and $1 \mathrm{mM}$ sodium orthovanadate. Immunoblottings for ARC, RIP3, and FADD were carried out through first conjugating HRP onto respective primary antibodies using Lynx Rapid HRP Antibody Conjugation Kit as described (AbD Serotec, Raleigh, NC, USA) and detected with ChemiDoc MP Imaging System (Bio-Rad, Hercules, CA, USA). Protein A, HRP conjugate (Millipore, Billerica, MA, USA) was used to detect primary antibody with the ChemiDoc MP Imaging System (Bio-Rad) and analyzed using the Image Lab software (Hercules, CA, USA). In vitro pull-down experiments were done using anti-HA Affinity Matrix (Roche Applied Science) and imaged with ODYSSEY Infrared Imaging Systems (Li-COR).
Cell death induction and analysis. Mouse TNF $\alpha(100 \mathrm{ng} / \mathrm{ml}$; R\&D Systems) was used to treat mouse L929 cells for the indicated times. Human TNF $\alpha$ was used in the experiments involving human Jurkat and MCF7 cell lines. Where indicated, cells were pretreated with $\mathrm{CHX}(1 \mu \mathrm{g} / \mathrm{ml}$; Sigma-Aldrich), z-VADfmk (50 $\mu \mathrm{M}$; R\&D Systems), or necrostatin-1 (10 $\mu \mathrm{M}$; Enzo Life Sciences) for $1 \mathrm{~h}$ before stimulation with TNF $\alpha$. HMGB1 cellular release was assessed by subjecting media to SDS-PAGE for immunoblotting. For PARP cleavage assays, cells were lysed in $50 \mathrm{mM}$ Tris-Cl, pH 7.4, $150 \mathrm{mM} \mathrm{NaCl}, 1 \%$ (v/v) NP-40, 1\% (v/v) sodium azide, $1 \mathrm{mM}$ PMSF, and $1 \mathrm{X}$ protease inhibitor cocktail (Sigma-Aldrich) and immunoblotted. LDH release assays were performed using CytoTox-ONE Homogenous Membrane Integrity Assay (Promega). PI entry was assessed using $1 \mu \mathrm{g} / \mathrm{ml}$ (Sigma). Both LDH and PI assays were read using Wallac Victor ${ }^{2}$ Multilabel Counter Model 1420-011 (Perkin-Elmer, Waltham, MA, USA).

Cell fractionation and NF- $\kappa \mathrm{B}$ activation. Cells were treated with $10 \mathrm{ng} / \mathrm{ml}$ of TNF $\alpha$, collected, and resuspended in $250 \mu$ l of Buffer A (10 mM HEPES pH 7.5, $10 \mathrm{mM} \mathrm{KCl,} 0.1 \mathrm{mM}$ EDTA, 0.1 mM EGTA, $1 \mathrm{mM}$ DTT, 0.5 mM PMSF) and subsequently incubated on ice for $15 \mathrm{~min}$. In all, $15.62 \mu$ lof $10 \%$ IGEPAL were then added, vortexed for $10 \mathrm{~s}$, and centrifuged at $950 \times \mathrm{g}$ for $1 \mathrm{~min}$ at $4{ }^{\circ} \mathrm{C}$. The resulting supernatant is the cytosolic fraction. The pellet was resuspended in $100 \mu \mathrm{l}$ Buffer B (20 mM HEPES, 400 mM KCl, 1 mM EDTA, 1 mM EGTA, 1 mM DTT, 1 mM PMSF, $10 \%$ (v/v) glycerol), sonicated, and centrifuged at $20800 \times g$ to obtain the nuclear fraction. A total of $20 \mu \mathrm{g}$ of protein from the nuclear fraction was used for p65 ELISA (Transcription Factor Kit, Thermo Fisher Scientific).

RNA isolation, cDNA synthesis, and quantitative real-time PCR. RNA isolation was done using the RNeasy kit from Qiagen according to the protocol. cDNA synthesis was performed using SuperScript III First-Strand Synthesis System for RT-PCR (Life Technologies) according to the product protocol. Included are the primers specific for: Bcl-xL, forward $5^{\prime}$-TGACCACCTA GAGCCTTGGA-3' and reverse 5'-GCTGCATTGTTCCCGTAGA-3'; IL-6, forward $5^{\prime}$-GCTACCAAACTGGAT ATAATCAGGA-3' and reverse $5^{\prime}$-CCAGGTAGC TATGGTACTCCAGAA-3'; FLIP, forward 5'-GCAGAAGCTCTCCCAGCA-3' and reverse $5^{\prime}$-TTTGTCCATGAGTTCAACGTG-3'; iNOS, forward $5^{\prime}$-CTTTGCCACG GACGAGAC- $3^{\prime}$ and reverse 5'-TCATTGTACTCTGAGGGCTGAC-3'; and TRAF2, forward $5^{\prime}$-CTGCAGAGCACCCTGTAGC- $3^{\prime}$ and reverse $5^{\prime}$-AACTTGGGGCAG ACCTCATC-3'. 18S rRNA was used as internal housekeeping control for normalization (Applied Biosystems 4333760F, Grand Island, NY, USA). Taqman probes (Applied Biosystems) recommended for respective gene transcripts were used for quantitative RT-PCR. Assays were performed in triplicates, and the number of independent experiments is noted in figure legends.

Vaccinia virus infection. Vaccinia virus WR strain was prepared as described previously. ${ }^{52}$ We have previously described mice with generalized deletion of nol3, encoding ARC. ${ }^{29}$ These mice and wild-type controls were housed in Memorial-Sloan-Kettering Cancer Center, and animal infection experiments were performed in accordance with the protocols approved by the Institutional Animal Care and Use Committee. Vaccinia virus $1 \times 10^{6}$ plaque-forming units or the same volume of vehicle (phosphate-buffered saline) were administered intraperitoneally to 10-week-old wild-type and nol3-/ - male C57BL/6 mice. Visceral fat and liver were harvested 3 days post injection and fixed in $10 \%(\mathrm{v} / \mathrm{v})$ formalin for $72 \mathrm{~h}$. Paraffin-embedded tissues were sectioned at $4 \mu \mathrm{m}$ and stained with hematoxylin and eosin.

TNF $\alpha$-induced systemic inflammatory response syndrome. Recombinant mouse TNF $\alpha$ (R\&D Systems) $500 \mu \mathrm{g} / \mathrm{kg}$ body weight was injected intravenously through the tail vein in 10- to 14-week-old wild-type and nol3-I C57BL/6 mice. Mice were matched for gender and age. Rectal body temperature was recorded with electric thermometer (model THM 150; Indus Instruments, Houston, TX, USA) connected to Vevo 770 Imaging Station (VisualSonics, Toronto, ON, Canada). TNF $\alpha$-induced systemic inflammatory response syndrome experiments were performed in accordance with the protocols approved by the Albert Einstein College of Medicine Institutional Animal Care and Use Committee.

Statistical analysis. Data are presented as mean \pm S.E.M. $N$ is the number of independent experiments performed. Two-way ANOVA followed by Bonferroni's post test was used to compare data, with the exception of the in vivo vaccinia virus infection and TNF $\alpha$-induced systemic inflammatory response syndrome experiments. For the vaccinia virus infection model, the two-tailed Student's $t$-test was 
used to analyze significance. Repeated measure two-way ANOVA analysis was performed to analyze body temperatures of wild-type and ARC-deficient mice until $6 \mathrm{~h}$ post-TNF $\alpha$ injection. After $6 \mathrm{~h}$, mice injected with TNF $\alpha$ started dying and therefore resulting in missing values for analysis for further time points. The Kaplan-Meier survival analysis was used to test statistical significance of the survival curves between mice deficient in ARC expression and wild-type mice post-TNF $\alpha$ injections. All statistical analysis was carried out using the GraphPad Prism version 5.00 for Mac (GraphPad Software, San Diego, CA, USA, www.graphpad.com).

\section{Conflict of Interest}

The authors declare no conflict of interest.

Acknowledgements. We thank Dr. Ulrich Steidl, Dr. Jerry Chipuk, Dr. Mark Czaja, Dr. Fernando Macian, Dr. Evripidis Gavathiotis, and Dr. Wenjun Guo for their insights and suggestions. We also thank Dr. Ryung Kim for his assistance with statistical analysis. We thank Dr. Christina Medina-Ramirez and Dr. Melissa James for providing the ARC plasmids and generating ARC shRNA lentivirus. We also thank Min Zheng for maintaining the mice. We thank the Wilf family for their ongoing generosity and support. This work was supported by the National Institutes of Health Grants 5R01HL060665 (to RNK), 3P30CA013330 (to RNK), 5P60DK020541 (to RNK), K08AI073736 (to LD), 1R56Al095692 (to LD), and 5T32AG023475 (to GK). RNK is supported by The Dr. Gerald and Myra Dorros Chair in Cardiovascular Disease.

1. Strasser A, O'Connor L, Dixit VM. Apoptosis signaling. Annu Rev Biochem 2000; 69: 217-245.

2. Yuan J, Kroemer G. Alternative cell death mechanisms in development and beyond. Genes Dev 2010; 24: 2592-2602.

3. Vandenabeele P, Galluzzi L, Vanden Berghe T, Kroemer G. Molecular mechanisms of necroptosis: an ordered cellular explosion. Nat Rev Mol Cell Biol 2010; 11: 700-714.

4. Christofferson DE, Yuan J. Necroptosis as an alternative form of programmed cell death. Curr Opin Cell Biol 2010; 22: 263-268.

5. Nakagawa T, Shimizu S, Watanabe T, Yamaguchi O, Otsu K, Yamagata $\mathrm{H}$ et al. Cyclophilin D-dependent mitochondrial permeability transition regulates some necrotic but not apoptotic cell death. Nature 2005; 434: 652-658.

6. Baines CP, Kaiser RA, Purcell NH, Blair NS, Osinska H, Hambleton MA et al. Loss of cyclophilin D reveals a critical role for mitochondrial permeability transition in cell death. Nature 2005; 434: 658-662.

7. Degterev A, Huang Z, Boyce M, Li Y, Jagtap P, Mizushima N et al. Chemical inhibitor of nonapoptotic cell death with therapeutic potential for ischemic brain injury. Nat Chem Biol 2005; 1: 112-119.

8. Holler N, Zaru R, Micheau O, Thome M, Attinger A, Valitutti S et al. Fas triggers an alternative, caspase-8-independent cell death pathway using the kinase RIP as effector molecule. Nat Immunol 2000; 1: 489-495.

9. Micheau O, Tschopp J. Induction of TNF receptor I-mediated apoptosis via two sequential signaling complexes. Cell 2003; 114: 181-190.

10. Bertrand MJ, Milutinovic S, Dickson KM, Ho WC, Boudreault A, Durkin J et al. cIAP1 and CIAP2 facilitate cancer cell survival by functioning as E3 ligases that promote RIP1 ubiquitination. Mol Cell 2008; 30: 689-700.

11. Ea C-K, Deng L, Xia Z-P, Pineda G, Chen ZJ. Activation of IKK by TNFalpha requires sitespecific ubiquitination of RIP1 and polyubiquitin binding by NEMO. Mol Cell 2006; 22: 245-257.

12. Cho Y, Challa S, Moquin D, Genga R, Dutta Ray T, Guildford M et al Phosphorylation-driven assembly of the RIP1-RIP3 complex regulates programmed necrosis and virus-induced inflammation. Cell 2009; 137: 1112-1123.

13. Sun $\mathrm{L}$, Wang $\mathrm{H}, \mathrm{He} \mathrm{S}$, Chen $\mathrm{S}$, Liao $\mathrm{D}$, Wang $\mathrm{L}$ et al. Mixed lineage kinase domain-like protein mediates necrosis signaling downstream of RIP3 kinase. Cell 2012; 148: 213-227.

14. Vercammen D, Beyaert R, Denecker G, Goossens V, Van Loo G, Declercq W et al. Inhibition of caspases increases the sensitivity of $L 929$ cells to necrosis mediated by tumor necrosis factor. J Exp Med 1998; 187: 1477-1485.

15. He S, Wang L, Miao L, Wang T, Du F, Zhao L et al. Receptor interacting protein kinase 3 determines cellular necrotic response to TNF-alpha. Cell 2009; 137: 1100-1111.

16. Zhang D-W, Shao J, Lin J, Zhang N, Lu B-J, Lin S-C et al. RIP3, an energy metabolism regulator that switches TNF-induced cell death from apoptosis to necrosis. Science 2009; 325: 332-336.

17. Wang Z, Jiang H, Chen S, Du F, Wang X. The mitochondrial phosphatase PGAM5 functions at the convergence point of multiple necrotic death pathways. Cell 2012; 148 : 228-243.

18. Koseki T, Inohara N, Chen S, Nunez G. ARC, an inhibitor of apoptosis expressed in skeletal muscle and heart that interacts selectively with caspases. Proc Natl Acad Sci 1998, 95: 5156-5160.
19. Mercier I, Vuolo M, Jasmin J-F, Medina CM, Williams M, Mariadason JM et al ARC (apoptosis repressor with caspase recruitment domain) is a novel marker of human colon cancer. Cell Cycle 2008; 7: 1640-1647.

20. Nam Y-J, Mani K, Ashton AW, Peng C-F, Krishnamurthy B, Hayakawa Y et al. Inhibition of both the extrinsic and intrinsic death pathways through nonhomotypic death-fold interactions. Mol Cell 2004; 15: 901-912.

21. Vercammen D, Vandenabeele P, Beyaert R, Declercq W, Fiers W. Tumour necrosis factorinduced necrosis versus anti-Fas-induced apoptosis in L929 cells. Cytokine 1997; 9: 801-808.

22. Hitomi J, Christofferson DE, Ng A, Yao J, Degterev A, Xavier RJ et al. Identification of a molecular signaling network that regulates a cellular necrotic cell death pathway. Cell 2008: 135: 1311-1323.

23. Kaufmann SH, Desnoyers S, Ottaviano Y, Davidson NE, Poirier GG. Specific proteolytic cleavage of poly(ADP-ribose) polymerase: an early marker of chemotherapy-induced apoptosis. Cancer Res 1993; 53: 3976-3985.

24. Scaffidi P, Misteli T, Bianchi ME. Release of chromatin protein HMGB1 by necrotic cells triggers inflammation. Nature 2012; 418: 191-195.

25. Aravind L, Dixit VM, Koonin EV. The domains of death: evolution of the apoptosis machinery. Trends Biochem Sci 1999; 24: 47-53.

26. Hofmann $\mathrm{K}$, Bucher $\mathrm{P}$. The CARD domain: a new apoptotic signalling motif. Trends Biochem Sci 1997; 22: 155-156.

27. Vaughn DE, Rodriguez J, Lazebnik Y, Joshua-Tor L. Crystal structure of Apaf-1 caspase recruitment domain: an alpha-helica greek key fold for apoptotic signaling. J Mol Biol 1999; 293: 439-447.

28. Chou JJ, Matsuo H, Duan H, Wagner G. Solution structure of the RAIDD CARD and model for CARD/CARD interaction in caspase-2 and caspase-9 recruitment. Cell 1998; 94 : $171-180$.

29. Medina-Ramirez CM, Goswami S, Smirnova T, Bamira D, Benson B, Ferrick N et al. Apoptosis inhibitor ARC promotes breast tumorigenesis, metastasis, and chemoresistance. Cancer Res 2011; 71: 7705-7715.

30. Duprez L, Takahashi N, Van Hauwermeiren F, Vandendriessche B, Goossens V, Vanden Berghe $T$ et al. RIP kinase-dependent necrosis drvies lethal systemic inflammatory response syndrome. Immunity 2011; 35: 908-918.

31. Vanlangenakker $\mathrm{N}$, Bertrand $\mathrm{MJ}$, Bogaert $\mathrm{P}$, Vandenabeele $\mathrm{P}$, Vanden Berghe $\mathrm{T}$. TNF-induced necroptosis in L929 cells is tightly regulated by multiple TNFR1 complex I and II members. Cell Death Dis 2011; 2: 1-10.

32. Golstein P, Kroemer G. Cell death by necrosis: towards a molecular definition. Trends Biochem Sci 2006; 32: 37-43.

33. Zheng L, Bidere N, Staudt D, Cubre A, Orenstein J, Chan FK-M et al. Competitive control of independent programs of tumor necrosis factor receptor-induced cell death by TRADD and RIP1. Mol Cell Biol 2006; 26: 3505-3514.

34. Doi TS, Marino MW, Takahashi T, Yoshida T, Sakakura T, Old LJ et al. Absence of tumor necrosis factor rescues RelA-deficient mice from embryonic lethality. Proc Natl Acad Sci USA 1999; 96: 2994-2999.

35. Alcamo E, Mizgerd JP, Horwitz BH, Bronson R, Beg AA, Scott M et al. Targeted mutation of TNF receptor I rescues the RelA-deficient mouse and reveals a critical role for NF-kB in leukocyte recruitment. J Immunol 2001; 167: 1592-1600.

36. Rosenfeld ME, Prichard L, Shiojiri N, Fausto N. Prevention of hepatic apoptosis and embryonic lethality in RelATNFR-1 double knockout mice. Am J Pathol2000; 156: 997-1007.

37. An J, Mehrhof F, Harms C, Lattig-Tunnemann G, Lee SL, Endres M et al. ARC is a novel therapeutic approach against acetaminophen-induced hepatocellular necrosis. $J$ Hepatol 2013; 58: 297-305

38. Simpson KJ, Lukacs NW, McGregor AH, Harrison DJ, Strieter RM, Kunkel SL. Inhibition of tumour necrosis factor alpha does not prevent experimental paracetamol-induced hepatic necrosis. J Pathol 2000; 190: 489-494.

39. James L, Kurten R, Lamps L, McCullough S, Hinson J. Tumour necrosis factor receptor 1 and hepatocyte regeneration in acetaminophen toxicity: a kinetic study of proliferating cell nuclear antigen and cytokine expression. Basic Clin Pharmacol Toxicol 2005; 97: 8-14.

40. Whelan RS, Kaplinskiy V, Kitsis RN. Cell death in the pathogenesis of heart disease: mechanisms and significance. Annu Rev Physiol 2010; 72: 19-44.

41. Engidawork E, Gulesserian T, Yoo BC, Cairns N, Lubec G. Alteration of caspases and apoptosis-related proteins in brains of patients with Alzheimer's disease. Biochem Biophys Res Commun 2001; 281: 84-93.

42. Nam Y-J, Mani K, Wu L, Peng C-F, Calvert JW, Foo RS et al. The apoptosis inhibitor ARC undergoes ubiquitin-proteasomal-mediated degradation in response to death stimuli. J Biol Chem 2007; 282: 5522-5528.

43. Hong Y-M, Jo D-G, Lee J-Y, Chang J-W, Nam J-H, Noh JY et al. Down-regulation of ARC contributes to vulnerability of hippocampal neurons to ischemia/hypoxia. FEBS Lett 2003; 543: 170-173

44. Zong W-X, Ditsworth D, Bauer DE, Wang Z-Q, Thompson CB. Alkylating DNA damage stimulates a regulated form of necrotic cell death. Genes Dev 2004; 18: 1272-1282.

45. Nehs MA, Lin C-I, Kozono DE, Whang EE, Cho NL, Zhu K et al. Necroptosis is a novel mechanism of radiation-induced cell death in anaplastic thyroid and adrenocortical cancers. Surgery 2011; 150: 1032-1039.

46. Kreuzaler P. Watson CJ. Killing a cancer: what are the alternatives? Nat Rev Cancer 2012; 12: $411-424$. 
47. Long J, Ryan K. New frontiers in promoting tumour cell death: targeting apoptosis, necroptosis and autophagy. Oncogene 2012; 31: 1-16.

48. Wu L, Nam Y-J, Kung G, Crow MT, Kitsis RN. Induction of the apoptosis inhibitor ARC by Ras in human cancers. J Biol Chem 2010; 285: 19235-19245.

49. Wang M, Qanungo S, Crow MT, Watanabe M, Nieminen A-L. Apoptosis repressor with caspase recruitment domain (ARC) is expressed in cancer cells and localizes to nuclei. FEBS Lett 2005; 579: 2411-2415.

50. Mercier I, Vuolo M, Madan R, Xue X, Levalley AJ, Ashton AW et al. ARC, an apoptosis suppressor limited to terminally differentiated cells, is induced in human breast cancer and confers chemo- and radiation-resistance. Cell Death Differ 2005; 12: 682-686.

51. Pear W, Scott M, Nolan G. Generation of high titre, helper-free retroviruses by transient transfection. In: Robbins P (ed). Methods in Molecular Medicine: Gene Therapy Protocols. Human Press: Totowa, NJ, USA, 1997, pp 41-57.

52. Deng L, Dai $P$, Ding W, Granstein RD, Shuman S. Vaccinia virus infection attenuates innate immune responses and antigen presentation by epidermal dendritic cells. $J$ Virol 2006; 80: 9977-9987.

Supplementary Information accompanies this paper on Cell Death and Differentiation website (http://www.nature.com/cdd) 